\title{
Business centre or bedroom community? The development of employment in small and medium-sized towns
}

\author{
David Kaufmann \& Stefan Wittwer
}

Published in Regional Studies, https://doi.org/10.1080/00343404.2019.1585529

David Kaufmann, University of Bern, KPM Center for Public Management, Switzerland, david.kaufmann@kpm.unibe.ch

Stefan Wittwer, University of Bern, KPM Center for Public Management, Switzerland stefan.wittwer@kpm.unibe.ch

\begin{abstract}
This study scrutinizes the development of employment towards business centres or bedroom communities in Swiss small and medium-sized towns (SMSTs). We analyse an original data set of all 152 SMSTs in Switzerland. Bayesian multi-level and spatial regression techniques examine regional and local explanatory factors affecting the development of employment. We find evidence for employment growth if an SMST is embedded in a dynamic network, meaning that employment growth in neighbouring cities and towns creates spillover effects for SMSTs. Thus, if local administrations want to influence their employment structure, they are well advised to engage in regional economic policy-making.
\end{abstract}

\section{KEYWORDS}

Small and medium-sized towns, employment, regional networks, local autonomy, spatial regression, spillover effects 


\section{INTRODUCTION}

The rapidly changing patterns of economic restructuring constantly challenge the economies of cities and towns. Smaller cities and towns are perceived to be especially exposed to the turmoil of economic globalization. Whereas the effects of economic restructuring on cities of global importance, and their policy responses, have been studied intensely (e.g. Brenner, 1999; Savitch and Kantor, 2002; Kaufmann, 2018), the ways in which small and mediumsized towns (SMSTs) are affected by changing economic patterns have not received the same amount of scholarly attention. SMSTs, defined as dense settlements with between 5,000 and 50,000 residents (Servillo et al., 2013), are often described as regional towns, rural towns, one-industry towns or economic lightweights (Bell and Jayne, 2006; Servillo et al., 2017), without an analysis of their capabilities to perform in the globalized economy.

Comparative studies of European cities demonstrate that population size is not a linear predictor for economic performance. In fact, SMSTs are catching up with large cities in terms of economic (and also population) growth (Dijkstra et al., 2013). They are central units in the European urban system given that Europe has been composed of networks of towns and small, medium and large cities for many decades (Hohenberg and Lees, 1995). Around 27 per cent of the European population currently lives in SMSTs (Servillo et al., 2017, 366).

However, SMSTs have largely been neglected by urban and regional research (Servillo et al., 2017; Meili and Mayer, 2017). It is necessary to examine small settlement structures in order to understand how they are able to develop competitive advantages in globalized interurban competition. Towns and small cities are 'much more than fillers, not (yet) cities or would-be cities - they are important nodes in the networks between places of different scales, and they are seen to mediate between the rural and the urban, as well as between the local and the global' (Bell and Jayne, 2006, 7). While Dijkstra et al. (2013) demonstrate the 
considerable growth dynamics that are taking place in European SMSTs, they have neither investigated explanations for this positive economic and demographic performance nor have they analysed employment in SMSTs.

This paper further scrutinizes the economic development of SMSTs by analysing factors that may explain the development of employment and, as a consequence, the economic specializations exhibited in SMSTs. Illustratively speaking, we seek to discover why some SMSTs have developed into (or have remained) business centres with employment in export-oriented sectors, while other SMSTs have become (or have remained) bedroom communities with residential economies. Theoretically speaking, the business centre profile matches the economic base theory that emphasizes the importance of export-oriented jobs for economic development (Massey, 1995; Storper and Scott, 2009). Economic base theory views industrial activities and high added value services as a prerequisite for economic development. Therefore, we include knowledge intensive business/financial services, high and low tech industries and tourism to the business centre profile. Conversely, the bedroom community profile exemplifies the revisited economic base theory that emphasizes the importance of residents for the economic development of a locality (Markusen and Schrock, 2009; Segessemann and Crevoisier, 2016). We include jobs that produce goods and services for the residents to the bedroom community category. In a next analytical step, we investigate local and regional determinants of employment development and thereby add to the debate between the importance of 'regional determinism vs. territorial autonomy' for the economic performance of cities and towns (e.g. Servillo et al., 2017; Tödtling and Trippl, 2005).

We choose to study Swiss SMSTs because they are embedded in growing metropolitan regions, their economic specializations vary considerably (Meili and Mayer, 2017; Kaufmann and Meili, 2019) and Swiss local governments enjoy comparatively very high 
autonomy (Sellers and Lidström, 2007). Accordingly, Swiss SMSTs operate in a highly dynamic economic context and their high local autonomy may provide them with the policy instruments necessary to influence their employment structure.

This interdisciplinary paper integrates theories from regional studies, economic geography and political science in order to derive five potential explanatory factors for the development of employment in SMSTs. The quantitative analysis uses Bayesian multi-level and spatial regression techniques and examines an original data set of employment data in all 152 Swiss SMSTs between 1995 and 2013. In the discussion of the results, we confront the quantitative findings with qualitative insights about Swiss SMSTs in order to test and enhance the reliability of the quantitative findings. Thus, we simulate a multi-method research design (Seawright, 2016). This paper finds employment growth in SMSTs that are integrated in a dynamic network of other SMSTs and cities. This suggests that spillover effects are the main influencer of employment in SMSTs and that development of employment is largely exogenous to local policy-making.

\section{SMALLER CITIES AND TOWNS IN A GLOBALIZED ECONOMY}

Economic globalization has pushed cities of various sizes into a rapidly changing and global economic playing field (Kaufmann and Arnold, 2018; Kaufmann, 2018). Along with greater exposure to global economic pressures, the position of cities has been strengthened as they have become the places where crucial production factors are concentrated (Brenner, 1999). In this globalized economic competition, cities and towns with small populations are perceived as victims of the centripetal forces of economic globalization (Kaufmann and Arnold, 2018). It is argued that smaller cities lack the critical mass needed to participate in interurban competition, that they lack research and development functions, and that they are 
unable to benefit from agglomeration economies in the way that larger cities can (Turok, 2004; Polèse, 2005). In addition, smaller cities may especially suffer because their pathdependent industrial specializations may have led to an undiversified economy or even to their conversion into one-industry towns (Hamdouch et al., 2017).

This type of globalization literature all too often reduces smaller cities to their functions as peripheral or regional capitals, or as marginalized parts of metropolitan regions (Bell and Jayne, 2006; Robinson, 2002). Similarly, Meijers and Burger (2017, 5) argue that 'smaller cities that surround larger cities are merely considered part of the urban hinterland from which larger cities draw support for urban functions'. As a consequence, smaller cities and towns have mostly been studied in light of rural economic development (Courtney and Moseley, 2008). Recent research on the economic performance of smaller European cities does not confirm these pessimistic assumptions. For example, Dijkstra et al. (2013) examine the growth dynamics of different urban types in EU15 nations and show that, since 2001, SMSTs have registered similar economic and demographic growth rates than their larger counterparts. While there is only a thin body of research that studies the economic development of smaller cities, there is even less research on the economic development of SMSTs.

Economic globalization may be either a threat or a chance for SMSTs. On the one hand, a SMST may develop into a business centre. Such an SMST may occupy an economic niche, or it can position itself as an alternative that is potentially more affordable or less congested for doing business. On the other hand, SMSTs may develop into bedroom communities or residential towns. The economy of residential towns serves the needs of their residents while neglecting export-oriented economic sectors (Hamdouch et al., 2017; Segessemann and Crevoisier, 2016). Becoming a bedroom community is not necessarily negative for SMSTs because their residential economy can also generate local business activity and employment 
(Markusen and Schrock, 2009; Segessemann and Crevoisier, 2016). Such SMSTs may be attractive for wealthy residents. Taxing these residents allows towns to increase their personal income tax base. The socio-economic development of residential towns may be even more stable than business centres, since they are not directly exposed to the competitive economic restructuring caused by globalization (Davezies, 2009).

\section{EXPLANATORY FACTORS FOR EMPLOYMENT DEVELOPMENT IN SMALL AND MEDIUM-SIZED TOWNS}

Most of the economic geography literature that examines the socio-economic development of SMSTs is located on a continuum that stresses the importance of regional or local factors. This continuum can be described as 'regional determinism vs. territorial autonomy' (Servillo et al., 2017; Tödtling and Trippl, 2005). For example, Giffinger and Suitner (2015, 1172) claim that ' $(. .$.$) cities need to be attractive not as single nodes, but as part of an urban$ region'. It is argued that SMSTs are therefore dependent on regional, or even international, economic and political developments and thus, 'the localness of the interests and identities driving the politics forward can be almost totally obscured' (Cox, 1998, 19). However, high local autonomy may enable SMSTs to counter or manage regional and international pressures to a certain degree. 'Territorial autonomy' emphasizes the importance of local agency and local policies in the socio-economic development of SMSTs (e.g. Knox and Mayer, 2009; Lorentzen and van Heur, 2012).

Against this backdrop, we derive three regional explanatory factors and two local explanatory factors for the development of employment, and we formulate hypotheses for each of these explanatory factors. The three regional explanatory factors represent a functional explanation (network density), a spatial explanation (distance to a metropolitan 
centre), and a knowledge-generation explanation (Higher Education Institutions). The two local explanatory factors capture the role of politics (local politics) and policy (taxes) on the development of employment. The variance in formal territorial autonomy is limited in this study, given that we analyze SMSTs that are embedded in the same national institutional setting.

\section{Regional explanatory factors}

Network density: There is an explicit regional dimension to spillover effects (SegarraBlasco et al., 2018). SMSTs may benefit from employment growth in neighbouring towns and cities. Due to spillover effects, an increase in employment in neighbouring towns and cities may induce employment growth in an SMST's own locality. SMSTs' may compensate their relative lack of size or mass by being very well embedded in networks of cities' (Meijers et al., 2016, 183). In this regard, the concept of borrowing size is fruitful because it suggests that SMSTs may 'borrow' some benefits (e.g. well-qualified human resources), as well as some functions (e.g. cultural amenities), from their neighbouring towns and cities (Alonso, 1973; Meijers et al., 2016; Meijers and Burger, 2017). The concept of borrowing size requires a network perspective for studying cities within a metropolitan region (Meijers

et al., 2016). SMSTs may also 'borrow size' from each other even without a neighbouring big city (Meijers and Burger, 2017).

Hypothesis 1.1: The denser the network in which an SMST is located and the more dynamic the network, the higher is the development of export-oriented employment.

Distance to a metropolitan centre: SMSTs that are well-connected to the centre of a metropolitan region may benefit from metropolitan functions, such as financial and business services, creative industries and global transportation (Hall and Pain, 2006; Meijers et al., 2016). SMSTs that are closer to the core city of a metropolitan region are likely to be more 
specialized than towns farther away from the urban core (Polèse and Shearmur, 2006). SMSTs close to the centre of a metropolitan region may experience employment growth, especially in knowledge-intensive services (Polèse and Shearmur, 2006; Servillo et al., 2017). In Switzerland, SMSTs that are close to the centre of a metropolitan region and that have well-established transport connections are able to attract knowledge-intensive firms (Glanzmann et al., 2006; Meili and Mayer, 2017). All in all, the distance to the centre of a metropolitan region is assumed to be important because agglomeration benefits attenuate with distance to the metropolitan core (Viladecans-Marsal, 2004).

Hypothesis 1.2: The closer an SMST is to a metropolitan centre, the higher is the development of export-oriented employment.

Higher Education Institutions (HEIs): HEIs have emerged as central actors in today's knowledge-intensive economy. HEIs are referred to as 'knowledge creators', 'knowledge circulators' or 'catalyst' for knowledge production (e.g. Bramwell and Wolfe, 2008; Benneworth and Nieth, 2018). HEIs include universities, technical universities or universities of applied sciences (Benneworth and Nieth, 2018). These HEIs can contribute to economic development and employment growth in various ways, such as by producing (commercializable) innovation (Benneworth and Nieth, 2018), by conducting basic research that provides specialized expertise and facilities for on-going, firm-based R\&D activities (Bramwell and Wolfe, 2008), by enabling firms to access knowledge from 'global pipelines' of international academic research networks (Bathelt et al., 2004; Bramwell and Wolfe, 2008) and by attracting and educating talent (Bramwell and Wolfe, 2008; Mayer, 2007). Thus, HEIs are an important underlying component of, what Tödtling and Trippl (2005) describe as, regional knowledge generation subsystems (Mayer, 2007). Especially in more peripheral regions, HEIs are important to contribute to the regional knowledge generation subsystem (Benneworth and Nieth, 2018). Hence: 
Hypothesis 1.3: To the more HEIs an SMST is closely located, the higher is the development of their export-oriented employment.

\section{Local explanatory factors}

Local politics: Local politics may influence local economic development trajectories. For example, Devecchi (2016) finds different local governance types in local planning processes in Swiss municipalities and links them, among others, to the political orientation of the electorate and the leadership of a municipality. In general, the classic left-right axis maps an economic conflict between state interventions and market solutions (Kriesi et al., 2008) and indicates that rightist parties prioritize economic growth as a development strategy. Given the high autonomy of Swiss municipalities, local political leaders are able to formulate a wide range of local economic development policies (Kaufmann and Arnold, 2018). We assume that in municipalities with a more rightist electorate, leaders formulate local economic development policies that aim to stimulate export-oriented industries.

Hypothesis 2.1: The more an SMST has a rightist electorate, the higher is the development of export-oriented employment.

Taxes: Research on tax policy follows the tradition of Tiebout (1956), who argues that local governments compete for mobile capital. The economic literature on local taxes can be summarized as that a decrease in taxes increases employment ceteris paribus (Wolman, 2012). Switzerland offers a highly interesting case in which to examine tax competition because of its high local tax autonomy (Brühlhart et al., 2015; Sellers and Lidström, 2007). Switzerland is the only country in Europe where sub-national jurisdictions, i.e. the cantons and municipalities, have considerable power to tax individual and corporate incomes. Furthermore, Swiss local governments can determine their own tax rates. As a consequence, the differences in (effective) tax rates across Swiss cantons are much more marked than those in any other European country (Feld and Reulier, 2009, 93). We therefore assume that: 
Hypothesis 2.2: The lower the taxes of an SMST, the higher is the development of export-oriented employment.

Local control variables: We include two controls in our analysis that account for local factors, namely population size and economic specialization. We treat these local factors as controls because we are interested in how local policy makers can influence the development of employment. These two controls are path-dependent local factors and therefore they are hard to influence by local policy-making. We include population size because larger towns, within the range of the SMST definition, are often considered to have a competitive advantage in interurban competition over smaller cities. More populated SMSTs may offer a denser concentration of economic activities and are therefore less dependent on neighbouring towns or cities. Furthermore, the economic specialization of SMSTs may have an influence on the development of employment. We therefore control for the stock of export-oriented firms and the strength of different economic sectors in 1995. Meili and Mayer (2017) find that Swiss SMSTs with a high share of employment in the service industry tend to be more economically dynamic. ${ }^{1}$

\section{RESEARCH DESIGN}

\section{Case selection: Swiss SMSTs}

We are interested in the smallest, arguably most vulnerable, type of urban settlement. On the European level, Servillo et al. (2013) propose a classification of towns and Dijkstra and Poelman (2012) do the same for cities (see Table A4 in the appendix). The classification of urban settlements by the Swiss Federal Statistical Office integrates European definitions of both towns and cities. Urban settlements are defined as dense settlement forms that have a 
minimum of 5,000 residents living within their administrative boundaries (see Goebel and Kohler, 2014).

Europe may be at the forefront of the research on polycentric networks of smaller cities and SMSTs due to the large presence of these settlement types across Southern England, the Benelux countries, Western Germany, Switzerland and Northern Italy. We choose to study SMSTs in Switzerland because they are embedded in a growing and polycentric urban system, they are a very common settlement type in Switzerland, their economic specializations vary (Meili and Mayer, 2017) and they enjoy a comparatively very high autonomy (Sellers and Lidström, 2007). Given that we explicitly search for local explanatory factors, the high local autonomy makes Swiss SMSTs most-likely cases, meaning that there is a higher likelihood of finding local policies that influence the development of employment in Swiss SMSTs than in SMSTs in other Western European countries. 
Figure 1: Small and medium-sized towns in Switzerland

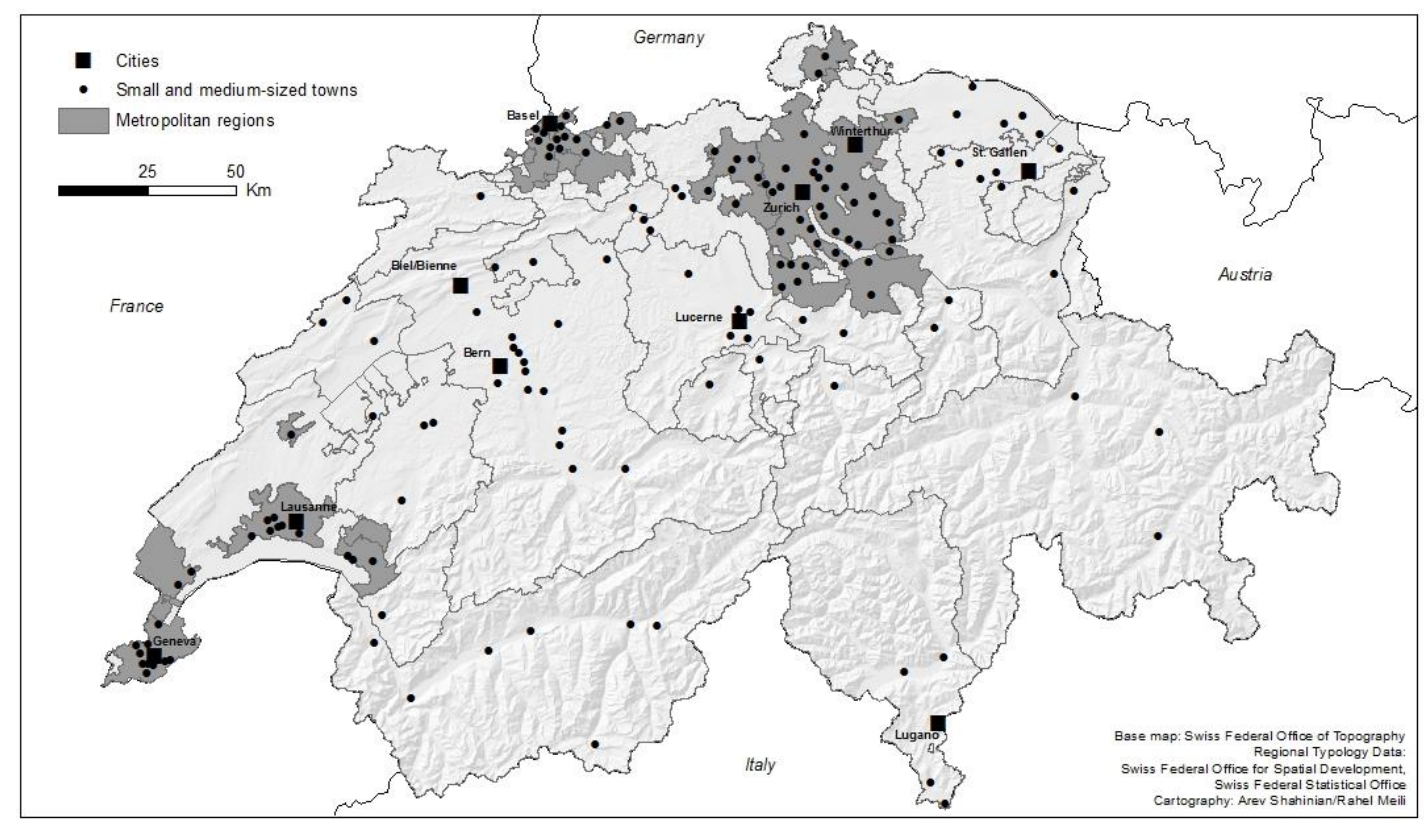

Notes: Lugano and the four SMSTs around it belong to the metropolitan region of Milano,

Italy, which is not shown in the map. This map was created by Arev Shahinian and Rahel

Meili (University of Bern) and is published with the permission of the copyright holders.

\section{Operationalization and model}

Our sample includes a full census of all of the 152 Swiss SMSTs. Descriptive statistics of the dependent and independent variables and a correlation table is provided in the appendix (Tables A1 and A2). We conduct a quantitative analysis of the development of employment in these 152 SMSTs by examining the theoretically derived regional and local explanatory factors. We use the logarithmized development of full-time equivalent jobs in exportoriented economic sectors from 1995 to 2013 as the dependent variable. The number in the dependent variable equals all jobs in all economic sectors minus jobs in the residential economy. ${ }^{2}$ An increase in the dependent variable implies the SMST's development towards a business centre while a decrease or stagnation in the variable indicates that it either 
remains or becomes a bedroom community. We use regional and local explanatory factors as independent variables from both a dynamic (i.e. development from 1995 to 2013) and a static (i.e. average value) perspective.

To measure network density, we devise a new dataset that incorporates the location of SMSTs. Based on the literature on spatial interdependence and spatial regression modeling (Neumayer and Pluemper, 2016; Ward and Gleditsch, 2008), we define a binary matrix $C$ that specifies connectivities between SMSTs with an entry for SMST $i$ and SMST $j$ with $c_{i j}=$ 1 if a connection exists and $c_{i j}=0$ if there is no connection (Ward and Gleditsch, 2008, 14). In line with the literature, distance is calculated by a measurement of the transportation network via trains and not by physical distance. If a town is located within a driving distance of less than 20 minutes from the centre of a metropolitan region ${ }^{3}$, it is considered to have spatial proximity and is therefore coded as $1 .^{4}$ The result of this process is a connectivity matrix that shows which and to how many other SMSTs and cities each SMST is connected. The spatial lag of network density is measured by examining the amount of full-time equivalent jobs in the export-oriented economic sector of the neighbouring SMSTs of the SMST under observation. If SMST A is connected to SMST B and SMST C, where B has a value of 350 in full-time equivalency and $\mathrm{C}$ has a value of 500, the spatial lag of SMST A is 850. It can be assumed that the higher the value of the spatial lag, the denser SMST A is embedded in a city-network that has high job growth. In addition to the absolute value of jobs in neighbouring towns and cities, we also take into account the development of employment in the regional network by measuring how many full-time equivalent jobs in the export-oriented economic sector neighbouring towns and cities won or lost during the time period in question. The spatial lag variables also consider whether or not SMSTs are located close to large cities ${ }^{5}$, where the city-network is supposed to be denser than in peripheral networks of towns. 
Neumayer and Pluemper (2016) argue that, even though the variables that measure distance by spatial proximity are not subject to being endogenous (see also LeSage and Pace, 2011; Kelejian and Prucha, 2010), they are only valid if they are theoretically grounded or highly correlated with the true interactions and relations between the observations, which constitute the actual causal mechanism. Because this paper focuses on locational aspects, spatial proximity is of fundamental interest and acts as an important explanatory variable for the development of employment. Therefore, measuring network density by geographical proximity acts as a proxy for city-network characteristics.

To assess the distance from SMSTs to the centre of their respective metropolitan regions ${ }^{6}$, we measure the distance in train minutes for each SMST to its nearest metropolitan centre. HEIs are measured by accounting for all universities, technical universities and universities of applied science in Switzerland. We thereby take advantage of the connectivity matrix described above, to measure whether an SMST hosts HEIs or has neighbours that do. Additionally, our model includes a political variable measuring the average election results for non-leftist parties in the Swiss federal election for the National Council and the average local income tax rate and the change of the tax rate from 1995 to 2013 (see the operationalization table A1 in the appendix for further information).

Subnational entities in Switzerland, i.e. the cantons, are the most powerful political entities with respect to policy making (Sager et al., 2017). We assume that the error terms are clustered at the cantonal level and we therefore run a Bayesian multi-level model (Gelman and Hill, 2007; Steenbergen and Jones, 2002; Stegmueller, 2013). ${ }^{7}$ We allow the intercept to vary across SMSTs in their respective cantons. ${ }^{8}$ In order to assess the weight of the three regional explanatory factors, we first run a model that only contains the variables that measure regional factors. In the second model, we add the local control variables before 
adding the variables measuring local political factors. Models 4-6 include controls for the strength in three distinct economic sectors in 1995.

\section{RESULTS AND DISCUSSION}

Table 1 presents the results of the regression analysis. ${ }^{9}$ In all of the models, the only hypothesized variable with a coefficient that is significantly different from 0 is the dynamic of the network that an SMST is embedded in. Thus, only hypothesis 1.1 can be supported. The effect remains robust independent of the inclusion of additional variables. In all of the other variables, the effect is around 0, i.e. negligible. As the Deviance Information Criterion (DIC) is lowest in the first model with the fewest variables, ${ }^{10}$ we can argue that a 10 per cent increase in export-oriented full-time equivalent jobs in neighbouring SMSTs and cities increases the number of full-time equivalent jobs in the observed SMSTs by 1.7 per cent. It is interesting to note that, when taking cantonal variance and the network density into account, HEIs, prior employment, population and political factors do not help to explain the development of employment. 
Table 1: Results of Bayesian multi-level estimates.

\begin{tabular}{|c|c|c|c|c|c|c|}
\hline & $\begin{array}{r}\text { (1) } \\
\Delta \text { empl }^{\mathrm{a}} \\
\end{array}$ & $\begin{array}{r}(2) \\
\Delta \text { empl }^{\mathrm{a}} \\
\end{array}$ & $\begin{array}{r}(3) \\
\Delta \text { empl }^{\mathrm{a}} \\
\end{array}$ & $\begin{array}{r}\text { (4) } \\
\Delta \text { empl }^{\mathrm{a}} \\
\end{array}$ & $\begin{array}{r}\text { (5) } \\
\Delta \text { empl }^{\mathrm{a}} \\
\end{array}$ & $\begin{array}{c}(6) \\
\Delta \mathrm{empl}^{\mathrm{a}} \\
\end{array}$ \\
\hline \multicolumn{7}{|l|}{ Regional explanatory factors } \\
\hline $\begin{array}{l}\text { Netw. density } \\
\text { (in 1995) }\end{array}$ & $\begin{array}{r}-0.002 \\
(0.012)\end{array}$ & $\begin{array}{r}0.002 \\
(0.012)\end{array}$ & $\begin{array}{r}0.003 \\
(0.012)\end{array}$ & $\begin{array}{r}0.003 \\
(0.012)\end{array}$ & $\begin{array}{r}0.003 \\
(0.012)\end{array}$ & $\begin{array}{r}0.004 \\
(0.012)\end{array}$ \\
\hline $\begin{array}{l}\text { Netw. density } \\
(\Delta \text { 1995-2013) }\end{array}$ & $\begin{array}{r}0.169 * * \\
(0.048)\end{array}$ & $\begin{array}{r}0.160 * * \\
(0.050)\end{array}$ & $\begin{array}{r}0.153 * * \\
(0.051)\end{array}$ & $\begin{array}{r}0.152^{* *} \\
(0.050)\end{array}$ & $\begin{array}{r}0.169 * * \\
(0.053)\end{array}$ & $\begin{array}{r}0.152 * * \\
(0.051)\end{array}$ \\
\hline $\begin{array}{l}\text { Distance } \\
\text { to metro centre }\end{array}$ & $\begin{array}{r}0.000 \\
(0.001)\end{array}$ & $\begin{array}{r}0.000 \\
(0.001)\end{array}$ & $\begin{array}{r}0.001 \\
(0.001)\end{array}$ & $\begin{array}{r}0.001 \\
(0.001)\end{array}$ & $\begin{array}{r}0.001 \\
(0.001)\end{array}$ & $\begin{array}{r}0.001 \\
(0.001)\end{array}$ \\
\hline $\begin{array}{l}\text { Higher education } \\
\text { institutions }\end{array}$ & $\begin{array}{r}-0.032 \\
(0.019)\end{array}$ & $\begin{array}{r}-0.036 \\
(0.020)\end{array}$ & $\begin{array}{r}-0.034 \\
(0.020)\end{array}$ & $\begin{array}{r}-0.035 \\
(0.020)\end{array}$ & $\begin{array}{r}-0.036 \\
(0.020)\end{array}$ & $\begin{array}{r}-0.034 \\
(0.020)\end{array}$ \\
\hline \multicolumn{7}{|l|}{ Local explanatory factors } \\
\hline $\begin{array}{l}\text { Politics } \\
\text { (share non-left parties) }\end{array}$ & & & $\begin{array}{r}-0.005 \\
(0.003)\end{array}$ & $\begin{array}{r}-0.005 \\
(0.003)\end{array}$ & $\begin{array}{r}-0.005 \\
(0.003)\end{array}$ & $\begin{array}{r}-0.005 \\
(0.003)\end{array}$ \\
\hline $\begin{array}{l}\text { Tax rate } \\
\text { (mean 1995-2013) }\end{array}$ & & & $\begin{array}{r}-0.021 \\
(0.020)\end{array}$ & $\begin{array}{r}-0.018 \\
(0.019)\end{array}$ & $\begin{array}{r}-0.021 \\
(0.019)\end{array}$ & $\begin{array}{r}-0.021 \\
(0.018)\end{array}$ \\
\hline $\begin{array}{l}\text { Tax rate } \\
(\Delta 1995-2013)\end{array}$ & & & $\begin{array}{r}-0.001 \\
(0.022)\end{array}$ & $\begin{array}{r}0.005 \\
(0.022)\end{array}$ & $\begin{array}{r}0.000 \\
(0.022)\end{array}$ & $\begin{array}{r}0.000 \\
(0.022)\end{array}$ \\
\hline \multicolumn{7}{|l|}{ Control variables } \\
\hline $\begin{array}{l}\text { Population } \\
(\Delta 1995-2013)\end{array}$ & & $\begin{array}{r}0.000 \\
(0.000)\end{array}$ & $\begin{array}{r}0.000 \\
(0.000)\end{array}$ & $\begin{array}{r}0.000 \\
(0.000)\end{array}$ & $\begin{array}{r}0.000 \\
(0.000)\end{array}$ & $\begin{array}{r}0.000 \\
(0.000)\end{array}$ \\
\hline $\begin{array}{l}\text { Population }^{\mathrm{a}} \\
\text { (mean 1995-2013) }\end{array}$ & & $\begin{array}{r}-0.038 \\
(0.057)\end{array}$ & $\begin{array}{r}-0.043 \\
(0.060)\end{array}$ & $\begin{array}{r}-0.068 \\
(0.057)\end{array}$ & $\begin{array}{r}-0.051 \\
(0.057)\end{array}$ & $\begin{array}{l}-0.050 \\
(0.056)\end{array}$ \\
\hline $\begin{array}{l}\text { Residential econ } \\
(\Delta \text { 1995-2013) }\end{array}$ & & $\begin{array}{r}0.000 \\
(0.000)\end{array}$ & $\begin{array}{r}0.000 \\
(0.000)\end{array}$ & $\begin{array}{r}0.000 \\
(0.000)\end{array}$ & $\begin{array}{r}0.000 \\
(0.000)\end{array}$ & $\begin{array}{r}0.000 \\
(0.000)\end{array}$ \\
\hline $\begin{array}{l}\text { Employment }{ }^{\mathrm{a}, \mathrm{b}} \\
\text { (in 1995) }\end{array}$ & & $\begin{array}{r}-0.009 \\
(0.035)\end{array}$ & $\begin{array}{r}-0.010 \\
(0.035)\end{array}$ & & & \\
\hline $\begin{array}{l}\text { Employment }{ }^{\mathrm{a}, \mathrm{b}} \\
\text { (in 1995) }\end{array}$ & & $\begin{array}{c}-0.009 \\
(0.035)\end{array}$ & $\begin{array}{r}-0.010 \\
(0.035)\end{array}$ & & & \\
\hline KIBS in $1995^{a}$ & & & & $\begin{array}{l}0.062 * \\
(0.029)\end{array}$ & & \\
\hline $\begin{array}{l}\text { Low tech } \\
\text { (in 1995) }\end{array}$ & & & & & $\begin{array}{r}0.023 \\
(0.029)\end{array}$ & \\
\hline $\begin{array}{l}\text { High tech }^{\mathrm{a}} \\
\text { (in 1995) }\end{array}$ & & & & & & $\begin{array}{l}-0.006 \\
(0.015)\end{array}$ \\
\hline Intercept & $\begin{array}{r}6.873 \\
(0.446)\end{array}$ & $\begin{array}{r}7.272 \\
(0.664)\end{array}$ & $\begin{array}{r}7.876 \\
(0.802)\end{array}$ & $\begin{array}{r}8.196 \\
(0.797)\end{array}$ & $\begin{array}{r}7.787 \\
(0.794)\end{array}$ & $\begin{array}{r}7.854 \\
(0.790)\end{array}$ \\
\hline $\mathrm{N}$ & 152 & 152 & 152 & 152 & 152 & $\overline{152}$ \\
\hline Deviance Information Criterion & -25.2 & -21.4 & -18.9 & -24.7 & -19.9 & -18.9 \\
\hline
\end{tabular}

Notes: Standard deviation in parentheses. One-sided Bayesian p-values reported: * p < 0:05, ** p $<0: 01$, *** p $<0: 001$

${ }^{\text {a }}$ Coefficients have been logarithmized.

b Time lag of the dependent variable in 1995. 
The only control that shows a significant effect on the development of employment is the share of KIBS jobs of SMSTs in 1995. This is as a path-dependent effect, meaning that SMSTs who already had a higher share of KIBS jobs were in a better position to gain new export-oriented jobs because the Swiss economy was mainly growing in knowledgeintensive and service-intensive industries.

The inclusion of the distance to the centre of metropolitan regions highlights that network density does not simply imply proximity to the metropolitan centre. The data shows that SMSTs close to the centres of metropolitan regions did not develop differently than SMSTs in other locations. Meanwhile, employment grew substantially stronger in SMSTs in a dense and dynamic network of other SMSTs and cities. This supports the argument that SMSTs that are closer to large cities can, and are more likely to, suffer from agglomeration shadows, which may counteract the potential beneficial effects of proximity (Meijers et al., 2016). SMSTs that are close to the centres of metropolitan regions may also specialize in residential economies and they may deliberately choose to reap the benefits of having wealthy residents (Segessemann and Crevoisier, 2016).

The multi-level approach in the analysis allows for the control of the mechanisms that take place at the cantonal level, due to its role as the most important political entity in the Swiss political system (Sager et al., 2017). As Figure A2 in the appendix shows, cantonal variance is considerable in the dependent variable. However, including the independent variables that measure regional determinism in Model 1 decreases the remaining unexplained variance between the cantons. ${ }^{11}$

We also conduct additional analyses in which we control for whether or not the political factors, namely the political orientation of the electorate and local tax rates, have an impact depending on their degree of embeddedness in a network of SMSTs and cities. ${ }^{12} \mathrm{We}$ find no indication that political factors only matter when SMSTs are located in isolated areas or 
when they are strongly integrated in a network. Considering the high local autonomy of Swiss local governments, it is interesting that local political factors had no systematic influence on SMSTs' development towards business centres or bedroom communities. Other research on local economic policy making in Switzerland seems to support this finding. With regard to the political orientation of the local electorate, Berli (2018) shows that structurally similar municipalities in Switzerland behave similarly in regard to local land-use planning despite different political attitudes. This points to a more functionalist behavior of local leaders: They are first and foremost concerned with tackling challenges at the local level and partisan preferences are only of secondary interest. With regard to tax rates, Segessemann and Crevoisier (2016) observe that wealthy residents tend to cluster in municipalities that possess a developed residential economy. This means that a residential economy and low tax rates can go hand in hand.

Since our sample contains all Swiss SMSTs, we can say that, between 1995 and 2013, SMSTs in Switzerland benefited from being embedded in a dynamic environment. Additionally, the share of KIBS jobs of SMST in 1995 is positively correlated with the development of export-oriented employment.

The short distance to a centre of a metropolitan region, the presence of HEIs, the prior stock of export-oriented jobs, the prior stock of residential jobs, the population size, the political orientation of the electorate and local tax rates show no clear effect on the development of employment.

\section{QUALITATIVE INSIGHTS}


The results of the different regression models indicate that there is still a considerable amount of variance in the dependent variable that we cannot explain with our theoretically derived variables. ${ }^{13}$ By making use of the multi-method research strategy (Seawright, 2016), we discuss case study research of Swiss SMSTs as qualitative vignettes in order to briefly examine whether the unexplained variance is due to idiosyncratic effects or to a misspecification of the quantitative model. We focus on the three advantages of case study research as an additional analysis that improves regression-based inferences, as outlined by Seawright (2016), namely: 1) evaluating the plausibility of hypothesized paths, 2) testing measurement quality 3) and searching for omitted variables.

First, we find some evidence of the importance of network density for employment growth in case studies about SMSTs in Zurich North, which is located between the city of Zurich and the airport of Zurich. This region has developed rapidly since the 1950s when land reserves in the Northern parts of the city of Zurich were exhausted. Zurich North is now a polycentric and well-connected region, which mainly features a headquarter and knowledgeintensive economy (Nüssli and Schmid, 2016). Kaufmann and Meili (2019) interviewed local decision makers in Zurich North and find that the economic development of these towns can only be understood within the context of the rapid growth of the entire region. Thus, Zurich North has specialized into a fast-growing knowledge-intensive economy due to spillover effects, without much influence of local political action. This supports the main effect found in our regression analysis.

Second, a case study on the town of Wädenswil (Kaufmann and Meili, 2019) highlights a measurement issue found in our dependent variable. Wädenswil hosts a campus of the Zurich University of Applied Science. The Swiss Federal Statistical Officce (SFSO) categorizes University of Applied Sciences' jobs as residential economy jobs. However, these jobs are as much research jobs as they are teaching jobs, especially when compared to 
jobs in the same SFSO category of primary and secondary education. The number of these jobs is marginal and thus this classification flaw does not distort our model.

Third, case study research identifies cantonal and local land-use planning as relevant explanatory factors that we did not incorporate into our regression analysis. Cantonal landuse planning strategies often designate growth areas within their territories. The cantons, and sometimes also the Swiss Confederation, finance the public transport system in these growth areas. Yet, most SMSTs have no parts designated as growth areas. Our multilevel model is able to control for inter-cantonal variation but not for intra-cantonal variation. However, since cantonal growth areas are only designated as such in places where established dynamic networks of SMSTs exist, including them as a variable would result in problems of reverse causality. Kaufmann and Meili (2019) identify local land-use planning as the only relevant local policy instrument to impact the economic development of Swiss SMSTs. Devecchi (2016) reveals, in nine case studies of Swiss SMSTs, that SMSTs differ in their ability to impact local land-use planning. Given this importance of local land-use planning and the complexity to assess its influence on the development of employment, it would be best to capture this potential omitted variable with qualitative in-depth interviews or through survey research.

In general, case study research supports the effect of network density and the importance of 'regional determinism' in explaining employment growth in Swiss SMSTs. Additionally, qualitative studies point to land-use planning as important in explaining the development of employment in SMSTs. Furthermore, the small size of our unit of analysis makes local employment numbers vulnerable to distortions caused by idiosyncratic events, such as a successful attraction of a big firm or a closure of a big local firm. Systematic patterns are thus difficult to find when analysing and comparing SMSTs. 


\section{CONCLUSION}

The goal of this paper is to find explanatory factors for the development of employment in Swiss SMSTs in order to scrutinize why some SMSTs have developed into bedroom communities while others have transformed into business centres. It is highly relevant to examine local economic processes of SMSTs in more detail, given the outcome of recent studies that highlight the good economic performance of SMSTs as well as the recent discussions about the agency of SMSTs in today's globalized economy (Dijkstra et al., 2013; Servillo et al., 2017). We derive five potential explanatory factors from an interdisciplinary set of theories stemming from regional studies, economic geography and political science. We locate the determinants of economic development between regional determinism, i.e. regional explanatory factors, and territorial autonomy, i.e local explanatory factors (Servillo et al., 2017; Tödtling and Trippl, 2005).

We choose to study SMSTs in Switzerland because they are embedded in a growing and polycentric urban system, they are a frequent settlement type in Switzerland, their economic specializations vary and they have comparably high local autonomy. This high local autonomy allows us to examine whether or not local governments can influence the development of employment in SMSTs. We conduct a quantitative analysis that draws on a full census of all 152 Swiss SMSTs from 1995 to 2013. The multilevel analysis controls for cantonal variation, and it employs spatial regression techniques to measure network effects.

The results indicate that SMSTs that are located in a dynamic regional network, i.e. located close to towns and cities that exhibit employment growth, experience an increase in full-time equivalent jobs in the export-oriented sector. Additionally, the share of KIBS jobs of SMSTs in 1995 is positively correlated with the development of export-oriented employment. Other regional and the local political explanatory factors show no significant effect in the time 
period in question. This means that the embeddedness in a dynamic network can explain the positive development of employment in Swiss SMSTs while the other examined explanatory factors can equally result in lower growth rates, stagnation or loss of jobs in export-oriented sectors. A discussion of qualitative studies reveals that the results of the quantitative analysis appear to be robust and plausible.

We are aware that the findings generated from analyses of Swiss SMSTs should be generalized with caution given the specific Swiss context and the small sample size that makes local economies vulnerable to distortions caused by idiosyncratic events. We analyze the development of employment in a full census of all 152 Swiss SMSTs. This entails that we analyze overall effects and, potentially, also opposite effects, meaning that we can not do justice to the economic development of every individual SMST. Yet, the findings in this paper are in line with Camagni et al. (2016) conclusion regarding the importance of network effects for European cities. They find that other factors, such as urban size, do not explain urban growth but that 'the upgrading over time of the quality of the entire metropolitan/regional system (...) has been identified as another important driver of the growth of the single cities belonging to that system' (p. 155). Given the scarcity of research about SMSTs, it would be interesting to expand future research to other countries with high local autonomy, such as Germany, or to countries that have a similar urban system, such as The Netherlands. We assume that a similar study in Germany or The Netherlands would also reveal that local explanatory factors do not influence the development of employment given that SMSTs in these countries possess a lower degree of local autonomy than in Switzerland, which constitutes a most-likely case to find an effect of local explanatory factors.

SMSTs are dependent on their regional networks and they lack substantial local agency to influence their economic development. Theoretically speaking, 'regional determinism' trumps 'territorial autonomy'. If local administrations want to generate jobs beyond the 
residential economy, this study advises them to coordinate their economic development policies on a regional level with other local governments. This is supported by Beer et al. (2019), who recommends that key individuals and agencies should reach out to others, either within their existing networks or through the formation of new connections. The strengthening of regional coordination structures, such as metropolitan council of government organizations, is thus in the interest of local governments. This is relevant in the case of Switzerland, where local governments are often reluctant to cooperate in regional coordination structures because of their fear of losing local autonomy (Kaufmann et al., 2016). Yet, this study suggests that local governments may gain local autonomy if they engage in economic policy-making at the regional level.

\section{NOTES}

1. We use the categorization of economic sectors provided by Meili and Mayer (2017), which are based on the Nomenclature generale des activites economiques (NOGA) (Eurostat, 2016)

2. See Figure A1 in the appendix for its distribution.

3. Using the online timetable of www.sbb.ch and GoogleMaps. Twenty minutes is considered to be a good proxy for a commuting distance that indicates closeness (Kloosterman and Musterd, 2001), given that reaching distances within Swiss cities also easily require more than 20 minutes driving time.

4. On average, Swiss SMSTs have 3.5 neighbors. The distribution of the number of neighbors is visible in Figure A4 in the appendix.

5. Cities with more than 50,000 inhabitants, such as Zurich or Geneva.

6. The centres of metropolitan regions are Zurich, Lausanne, Geneva, Basel, and Milano (Raumkonzept Schweiz, 2012) 
7. We used di use priors $\rho\left(\beta_{k}\right) \sim 1$ for the parameters and inverse Wishart priors $\rho\left(1 / \sigma^{2}{ }_{\mu 0}\right) \sim$ $\operatorname{Gamma}(0.01,0.01)$ for the variance component. All models are estimated using the Markov Chain Monte Carlo (MCMC) estimation in Stata15. We let the models run for 209999 iterations (resp. 50,000 for Models 4-6), with a respective burn-in of 10,000 (resp. 5,000 for Models 4-6) and a thinning of 2 (resp. 1 for Models 4-6). Extensive diagnostics based on the graphical inspection of the trajectories and the Raftery-Lewis and Brooks-Draper diagnostics lead to the conclusion that the chains have mixed well and converged.

8. See Figure A2 in the appendix for cantonal means of the dependent variable.

9. The models and variables have been tested for multicollinearity, heteroscedasticity, nonlinearity and influential outliers, see appendix, i.e. Figure A3. Variables with outliers have been logarithmized. Convergence diagnostics are included in the appendix B.

10. The lower the DIC, the better the model fits the data (see Gelman and Hill, 2007, 525526). Since only one variable is significant, and the DIC penalizes for additional parameters, the first model, unsurprisingly, fits best.

11. The coefficients regarding the political variables were also allowed to vary across cantons in order to control for the fact that SMSTs in cantons that are very active in promoting their SMSTs may only have a small political impact. The results, however, show that the cantonal variance of the coefficient is negligibly low, which is why the randomslope is not presented here.

12. See Table A3 and further explanations in the appendix.

13. This can be seen when comparing the predicted and observed values in the dependent variable.

Acknowledgements: The authors contributed equally to this article. We would like to thank Fritz Sager, Heike Mayer and Rahel Meili as well as the editors of Regional Studies and the 
anonymous referees for their useful comments. We also thank Rahel Meili and Arev Shahinian for help with data collection and the creation of the map. David Kaufmann and Stefan Wittwer were supported by the Swiss National Science Foundation under Grant Number 159324. 


\section{REFERENCES}

Alonso, W. (1973). Urban zero population growth. Daedalus, 102(4):191-206.

Bathelt, H., Malmberg, A., and Maskell, P. (2004). Clusters and knowledge: local buzz, global pipelines and the process of knowledge creation. Progress in Human geography, $28(1): 31-56$

Beer, A., Ayres, S., Clower, T., Faller, F., Sancino, A., and Sotarauta, M. (2019). Place leadership and regional economic development: a framework for cross-regional analysis. Regional Studies 53(2): 171-182.

Bell, D. and Jayne, M. (2006). Small cities: Urban experience beyond the metropolis. London: Routledge.

Benneworth, P. and Nieth, L. (2018). Universities and regional development in peripheral regions. In Universities and regional economic development, pages 1-13. Abingdon: Routledge.

Berli, J. (2018). Competition in local land use planning? Journal of Public Policy, 38(1):2756.

Bramwell, A. and Wolfe, D. A. (2008). Universities and regional economic development: The entrepreneurial university of waterloo. Research policy, 37(8):1175-1187.

Brenner, N. (1999). Globalisation as reterritorialisation: the re-scaling of urban governance in the European Union. Urban studies, 36(3):431-451.

Brülhart, M., Bucovetsky, S., and Schmidheiny, K. (2015). Taxes in cities. In Duranton, G., Henderson, V. J., and Strange, W. C., editors, Handbook of Regional and Urban Economies, volume 5B, pages 1123-1196. Amsterdam: Elsevier.

Camagni, R., Capello, R., and Caragliu, A. (2016). Static vs. dynamic agglomeration economies. Spatial context and structural evolution behind urban growth. Papers in Regional Science, 95(1):133-158. 
Courtney, P. and Moseley, M. (2008). Determinants of local economic performance: experience from rural England. Local Economy, 23(4):305-318.

Cox, K. R. (1998). Spaces of dependence, spaces of engagement and the politics of scale, or: looking for local politics. Political Geography, 17(1):1-23.

Davezies, L. (2009). L'économie locale résidentielle. Géographie, économie, société, 11(1):47-53.

Devecchi, L. U. (2016). Zwischenstadtland Schweiz. Bielefeld: transcript Verlag.

Dijkstra, L., Garcilazo, E., and McCann, P. (2013). The economic performance of European cities and city regions: Myths and realities. European Planning Studies, 21(3):334-354.

Dijkstra, L. and Poelman, H. (2012). Cities in Europe: the new OECD-EC definition. Regional Focus 1:2012.

Eurostat (2016). High-tech industry and knowledge-intensive services (htec). Reference metadata in euro sdmx metadata structure (esms). Technical report, Eurostat.

Feld, L. P. and Reulier, E. (2009). Strategic tax competition in Switzerland: Evidence from a panel of the Swiss cantons. German Economic Review, 10(1):91-114.

Gelman, A. and Hill, J. (2007). Data analysis using regression and multi-level hierarchical models, volume 1. Cambridge University Press NY, USA.

Giffinger, R. and Suitner, J. (2015). Polycentric metropolitan development: From structural assessment to processual dimensions. European Planning Studies, 23(6):1169-1186.

Glanzmann, L., Gabi, S., Kruse, C., Thierstein, A., and Grillon, N. (2006). European Metropolitan Region Northern Switzerland: Driving agents for spatial development and governance responses. In Hall, P. and Pain, K., editors, The Polyentric Metropolis. Learning from mega-city regions in Europe, pages 172-186. London: Earthscan.

Goebel, V. and Kohler, F. (2014). Raum mit städtischem Charakter 2012. Technical report, Swiss Federal Statistical Office. 
Hall, P. G. and Pain, K. (2006). The Polycentric Metropolis: learning from mega-city regions in Europe. Routledge.

Hamdouch, A., Demaziere, C., and Banovac, K. (2017). The socio-economic profiles of small and medium-sized towns: Insights from European case studies. Tijdschrift voor economische en sociale geografie, 108(4):456-471.

Hohenberg, P. M. and Lees, L. H. (1995). The making of urban Europe, 1000-1994. Harvard University Press.

Kaufmann, D. (2018). Varieties of Capital Cities: The Competitiveness Challenge for Secondary Capitals. Cheltenham: Edward Elgar Pub.

Kaufmann, D. and Arnold, T. (2018). Strategies of cities in globalised interurban competition: The locational policies framework. Urban Studies, 55(12):2703-2720.

Kaufmann, D. and Meili, R. (2019). Leaves in the wind? Local policies of small and medium-sized towns in metropolitan regions. European Planning Studies, 27(1):21-41.

Kaufmann, D., Warland, M., Mayer, H., and Sager, F. (2016). Bern's positioning strategies: Escaping the fate of a secondary capital city? Cities. The International Journal of Urban Policy and Planning, 53:120-129.

Kelejian, H. H. and Prucha, I. (2010). Specification and estimation of spatial autoregressive models with autoregressive and heteroskedastic disturbances. Journal of Econometrics, 157(1):53-67.

Kloosterman, R. C. and Musterd, S. (2001). The polycentric urban region: Towards a research agenda. Urban Studies, 38(4):623-633.

Knox, P. and Mayer, H. (2009). Small town sustainability: Economic, social, and environmental innovation. Basel: Birkhaeuser Verlag.

Kriesi, H., Grande, E., Lachat, R., Dolezal, M., Bornschier, S., Frey, T. (2008). West European politics in the age of globalization. Cambridge University Press Cambridge. 
LeSage, J. and Pace, R. K. (2011). Pitfalls in higher order model extensions of basic spatial regression methodology. The Review of Regional Studies, 41(1).

Lorentzen, A. and van Heur, B. (2012). Cultural political economy of small cities. London: Routledge.

Markusen, A. and Schrock, G. (2009). Consumption-driven urban development. Urban geography, 30(4):344-367.

Massey, D. (1995). Spatial divisions of labor: Social structures and the geography of production. London: Macmillan.

Mayer, H. (2007). What is the role of the university in creating a high-technology region? Journal of Urban Technology, 14(3):33-58.

Meijers, E. J. and Burger, M. J. (2017). Stretching the concept of 'borrowed size'. Urban Studies, 54(1):269-291.

Meijers, E. J., Burger, M. J., and Hoogerbrugge, M. M. (2016). Borrowing size in networks of cities: City size, network connectivity and metropolitan functions in Europe. Papers in Regional Science, 95(1):181-198.

Meili, R. and Mayer, H. (2017). Small and medium-sized towns in Switzerland: Economic heterogeneity, socioeconomic performance and linkages. Erdkunde, 71(4):313-332.

Neumayer, E. and Pluemper, T. (2016). W. Political Science Research and Methods, 4(1):175-193.

Nüssli, R. and Schmid, C. (2016). Beyond the urban-suburban divide: Urbanization and the production of the urban in Zurich North. International Journal of Urban and Regional Research, 40(3):679-701.

Polèse, M. (2005).Cities and national economic growth: a reappraisal. Urban Studies, 42(8):1429-1451. 
Polèse, M. and Shearmur, R. (2006). Growth and location of economic activity: The spatial dynamics of industries in Canada 1971-2001. Growth and Change, 37(3):362-395.

Raumkonzept Schweiz (2012). Raumkonzept Schweiz. Retrieved from

https://www.are.admin.ch/are/de/home/raumentwicklung-und-raumplanung/strategie-undplanung/raumkonzept-schweiz.html

Robinson, J. (2002). Global and world cities: a view from off the maps. International Journal of Urban and Regional Research, 26(3):531-554.

Sager, F., Ingold, K. M., and Balthasar, A. (2017). Policy-Analyse in der Schweiz. Besonderheiten, Theorien, Beispiele. Zurich: NZZ Libro.

Savitch, H. and Kantor, P. (2002). Cities in the international marketplace: The political economy of urban development in North America and Western Europe. Princeton University Press.

Seawright, J. (2016). Multi-method social science: Combining qualitative and quantitative tools. Cambridge University Press.

Segarra-Blasco, A., Arauzo-Carod, J.-M., and Teruel, M. (2018). Innovation and geographical spillovers: new approaches and empirical evidence. Regional Studies, 52(5):603-607.

Segessemann, A. and Crevoisier, O. (2016). Beyond economic base theory: The role of the residential economy in attracting income to Swiss regions. Regional Studies, 50(8):13881403.

Sellers, J. M. and Lidström, A. (2007). Decentralization, local government, and the welfare state. Governance, 20(4):609-632.

Servillo, L., Atkinson, R., and Hamdouch, A. (2017). Small and medium-sized towns in Europe: Conceptual, methodological and policy issues. Tijdschrift voor economische en sociale geografie, 108(4):365-379. 
Servillo, L., Atkinson, R., Smith, I., Russo, A., Sykora, L., Demazière, C., and Hamdouche, A. (2013). Town: Small and medium sized towns in their functional territorial context. Technical report, Luxembourg: ESPON.

Steenbergen, M. R. and Jones, B. S. (2002). Modeling multilevel data structures. American Journal of Political Science, 46(1):218-237.

Stegmueller, D. (2013). How many countries for multilevel modeling? A comparison of frequentist and Bayesian approaches. American Journal of Political Science, 57(3):748761.

Storper, M. and Scott, A. J. (2009). Rethinking human capital, creativity and urban growth. Journal of economic geography, 9(2):147-167.

Tiebout, C. M. (1956). A pure theory of local expenditures. Journal of political economy, 64(5):416-424.

Tödtling, F. and Trippl, M. (2005). One size fits all?: Towards a differentiated regional innovation policy approach. Research policy, 34(8):1203-1219.

Turok, I. (2004). Cities, regions and competitiveness. Regional studies, 38(9):1069-1083.

Viladecans-Marsal, E. (2004). Agglomeration economies and industrial location: city-level evidence. Journal of Economic geography, 4(5):565-582.

Ward, M. D. and Gleditsch, K. S. (2008). Spatial Regression Models, volume 155 of Series: Quantitative Applications in the Social Sciences. California: SAGE Publications.

Wolman, H. (2012). What cities do: How much does urban policy matter? In Mossberger, K., Clarke, S. E., and John, P., editors, The Oxford Handbook of Urban Politics, pages 415-441. Oxford University Press. 